Jurnal MAKSIPRENEUR, Vol. III, No. 2, Hal 1-15

\title{
PENGARUH MOTIVASI EKSTERNAL dan MOTIVASI INTERNAL TERHADAP KINERJA KARYAWAN PADA TK BUDI MULIA DUA PANDEANSARI
}

\author{
Efa Nur Cholis (echolis03@gmail.com) \\ Alumnus Fakultas Ekonomi Universitas Proklamasi 45 Yogyakarta \\ Djoko Wijono (dj.wijono@gmail.com) \\ Fakultas Ekonomi Universitas Proklamasi 45 Yogyakarta
}

\begin{abstract}
This study aimed to examine the influence of external and internal motivation on employee performance in TK Budi Mulia Dua Pandeansari. The sample in this study were all employees in TK Budi Mulia Dua Pandeansari. Samples were collected using a total sampling. There were 50 respondents who have met the necessary conditions. The analytical method used is multiple regression analysis. The results showed that the external and internal motivation effect on employee performance. The results of multiple regression analysis showed that the variables of external and internal motivation have coefficient of 0.703 and 0.450 . The results showed that the external and internal motivation has given Adjusted R Square of 0.575 or $57.5 \%$.
\end{abstract}

Keywords: external motivation, internal motivation, performance

\section{PENDAHULUAN}

Salah satu indikator karyawan berkualitas adalah mempunyai kinerja yang tinggi. Kinerja yang tinggi ini sangat diperlukan oleh institusi. Karyawan yang memiliki kinerja yang tinggi akan selalu sadar secara penuh mengenai tanggung jawabnya masing - masing dan berusaha melaksanakan segala tugas yang diberikan kepadanya dengan baik sesuai dengan kemampuan yang dimilikinya untuk mendapatkan hasil kerja yang maksimal. Kinerja karyawan merupakan faktor penting untuk mendukung keberhasilan suatu pekerjaan seseorang, baik dalam kapasitas pribadi maupun sebagai seorang anggota suatu organisasi.

Kinerja karyawan sangat ditentukan oleh adanya motivasi kerja. Motivasi kerja merupakan kekuatan atau sebagai pendorong seseorang 
untuk melakukan suatu kegiatan yang diwujudkan dalam bentuk perbuatan nyata. Dengan demikian, semakin tinggi motivasi yang dimiliki oleh seseorang karyawan, maka akan semakin tinggi pula kinerja yang dihasilkan, begitupun sebaliknya, semakin rendah motivasi yang dimiliki seseorang karyawan maka akan semakin rendah kinerja yang dihasilkan.

Motivasi merupakan hal yang sangat berperan penting dalam meningkatkan suatu aktifitas kerja seorang karyawan guna mencapai hasil kinerja yang lebih baik, sebab seorang karyawan yang mempunyai motivasi tinggi akan selalu berusaha dengan maksimal dan sebaik mungkin dalam menyelesaikan setiap pekerjaan yang ditugaskan kepadanya. Setiap orang atau karyawan mau bekerja pasti ada faktor yang mendorong dari dalam dirinya untuk melaksanakan suatu aktifitas kerja. Motivasi kerja ini merupakan kondisi seseorang yang mendorong seseorang untuk melaksanakan suatu kegiatan untuk mencapai tujuan organisasi maupun tujuan individual. Dengan adanya motivasi kerja yang tinggi dalam diri seseorang akan mendorong semangat kerja untuk dapat menyelesaikan tugas - tugasnya dengan baik dan tepat waktu.

Taman Kanak - Kanak Budi Mulia Dua Pandeansari Yogyakarta sebagai salah satu tempat pendidikan anak yang memperhatikan mutu dan kualitas pelayanan. Untuk peningkatan mutu dan pelayanan. TK Budi Mulia Dua Pandeansari berusaha meningkatan motivasi kerja karyawan agar kinerja karyawan meningkat.

Dalam penelitian ini ingin mengetahui pengaruh variabel motivasi eksternal (upah/gaji, kondisi kerja, supervisi, dan jaminan sosial) dan variabel motivasi internal (pekerjaan yang sesuai dengan keinginan, pekerjaan yang menarik, dan pekerjaan yang menantang) terhadap kinerja karyawan di TK Budi Mulia Dua Pandeansari.

Berdasarkan latar belakang yang telah diuraikan tersebut, maka peneliti tertarik ingin mengetahui:

1. Seberapa besar pengaruh variabel-variabel motivasi terhadap kinerja karyawan di TK Budi Mulia Dua Pandeansari?

2. Variabel motivasi apa yang paling tinggi menyumbang tingkat kinerja karyawan di TK Budi Mulia Dua Pandeansari?

\section{TELAAH TEORI}

\section{Definisi Motivasi Kerja}

Menurut As'ad (1995 : 45), motivasi seringkali diartikan dengan istilah dorongan.Dorongan atau tenaga tersebut meruakan jiwa dan jasmani untuk berbuat mencapai tujuan,sehingga motivasi merupakan suatu driving force yang menggerakan manusia untuk bertingkah laku,dan di dalam perbuatanya itu mempunyai tujuan tertentu". 
Motivasi adalah sesuatu yang menimbulkan proses pemberian dorongan bekerja kepada para bawahan sedemikian rupa sehingga mereka mau bekerja ikhlas demi tercapainya tujuan organisasi secara efisien.

\section{Tujuan Motivasi Kerja}

Didalam perusahaan motivasi mempunyai peranan yang sangat sangat penting dalam meningkatkan kinerja karyawan. Tujuan dalam memberikan motivasi kerja terhadap karyawan agar karyawan dapat melaksanakan tugasnya secara efektif dan efisien. Menurut Malayu S.P Hasibuan (2002 : 146) tujuan motivasi kerja antara lain sebagai berikut :

a. Meningkatkan kinerja kerja karyawan

b. Meningkatkan produktivitas kerja karyawan

c. Mempertahankan kestabilan karyawan perusahaan

d. Meningkatkan kedispilinan karyawan

e. Mengefektifitas pengadaan karyawan

f. Menciptakan suasana dan hubungan kerja yang baik

g. Meningkatkan loyalitas, kreatifitas dan partisipasi karyawan

h. Meningkatkan tingkat kesejahteraan karyawan

i. Meningkatkan rasa tanggung jawab karyawan terhadap tugas tugasnya.

\section{Motivasi Eksternal}

Menurut William Bwerther Jr dan Keith Davis dalam Sekardamayanti (2000 : 253) yang membedakan motivasi kerja menjadi motivasi eksternal dan internal. Motivasi eksternal menjelaskan kekuatan yang ada dalam individu yang dipengaruhi oleh faktor eksternal yang dikendalikan oleh manajer, yaitu meliputi penghargaan, kenaikan pangkat dan tanggung jawab. Motivasi eksternal meliputi hal - hal yang berkaitan pekerjaan, seperti halnya gaji atau upah, keadaan kerja dan kebijaksanaan perusahaan dan pekerjaan yang mengandung hal-hal seperti penghargaan, pengembangan dan tanggung jawab. Manajer perlu mengenal motivasi eksternal untuk mendapatkan tanggapan yang positif dari karyawannya. Tanggapan positif ini menunjukkan bahwa karyawannya sedang bekerja demi kemajuan organisasi. Manajer dapat menggunakan motivasi eksternal yang positif maupun negatif. Motivasi positif merupakan penghargaan atas prestasi yang sesuai, sedangkan motivasi negatif mengenakan sanksi jika prestasi tidak dapat dicapai. Berikut aspek - aspek motivasi tersebut :

a. Pemberian upah/gaji untuk memenuhi kebutuhan fisik minimal maupun untuk kebutuhan hidup minimal. Tanpa upah atau gaji yang layak sulit untuk mengharapkan atau bahkan memaksa Sumber Daya 
Manusia agar memberikan kontribusi maksimal dalam melaksanakan tugas pokoknya.

b. Kondisi kerja yang baik, perasaan puas dan senang dalam bekerja di lingkungan organisasi, sangat dipengaruhi oleh kondisi kerja, baik yang bersfat fisik/mateial maupun psikis/non material. Kondisi kerja yang bersifat fisik menyangkut faktor sarana dan prasarana, seperti luas ruangan termaksud, penataan dalam ruangan, ketersediaan perlengkapan dan peralatan kerja yang mutakhir dan lain sebagainya. Sedangkan faktor psikis/non material mengenai hubungan antara atasan dengan bawahan yang lain.

c. Supervisi yang baik sebagai kegiatan mengamati, menilai dan membantu Sumber Daya Manusia agar bekerja secara efektif dan efisien. Merupakan salah satu kegiatan perilaku organisasi, karena bertujuan untuk terus menerus memperbaiki, meningkatkan dan menyempurnakan ketrampilan dalam bekerja.

\section{Motivasi Internal}

Motivasi internal merupakan motivasi yang berasal dari dalam diri seseorang. Efek motivasi terhadap kinerja karyawan akan tercipta jika motivasi internal ini sudah ada. Motivasi internal berperan penting dalam menciptakan kinerja karyawan yang tinggi dan secara terus menerus. Berikut aspek - aspek motivasi tersebut :

a. Pekerjaan yang menyenangkan, pekerjaan yang bebas dari tekanan dan paksaan, di samping mudah atau tidak rumit pelaksanaanya. Namun pekerjaan yang berat dan komplek juga akan menyenangkan, jika dikerjakan dalam suasana kerja yang saling bantu membantu dan tolong menolong atau dalam suasana kerjasama yang efektif dan efisien.

b. Pekerjaan yang menarik, setiap Sumber Daya Manusia akan menyenangi bekerja dalam bidang yang sesuai dengan potensi, latar belakang pengalaman, pendidikan, ketrampilan dan keahlian atau profesionalisme yang dikuasainya. Kesesuaiannya itu membuat pekerjaanya dirasakan menarik karena mencakup sesuatu yang sudah dikenal dan dipahaminya.

c. Pekerjaan yang menantang, motivasi kerja tidak saja timbul karena pekerjaan yang menyenangkan, tetapi menantang untuk mencapai suatu prestasi, sebagai sukses yang diinginkan oleh setiap pekerja (SDM). Dengan kata lain pekerjaan yang menantang cenderung akan menimbulkan motivasi berprestasi melalui kemampuan berkompetisi secara sehat, dalam arti jujur dan sportif, sejalan dengan kemampuan bekerjasama yang efektif dan efisien. (William dan Davis dalam Sekardamayanti, 2000 : 253) 


\section{Pengertian Kinerja Karyawan}

Kinerja seorang karyawan merupakan hal yang bersifat individual, karena setiap karyawan mempunyai tingkat kemampuan berbeda-beda dalam mengerjakan tugasnya. Pihak manajemen dapat mengukur karyawan atas hasil kerjanya berdasarkan kinerja dari masing-masing karyawan.

Kinerja adalah sebuah aksi, bukan kejadian. Aksi kinerja itu sendiri terdiri dari banyak komponen dan bukan merupakan hasil yang dapat dilihat pada saat itu juga. Pada dasarnya kinerja merupakan sesuatu yang bersifat individual, karena setiap karyawan memiliki tingkat kemampuan yang berbeda dalam mengerjakan tugasnya. Kinerja tergantung pada kombinasi antara kemampuan, usaha, dan kesempatan yang diperoleh. Akan dilakukan dan tidak dilakukan dengan karakteristik kinerja individu. Pendapat di atas didukung oleh pernyataan dari Sunarto ( 2003: 20 ), yaitu : Kinerja yang tinggi dapat tercapai oleh karena kepercayaan (trust) timbal balik yang tinggi antara anggota-anggotanya, artinya para anggota mempercayai integritas, karakteristik, dan kemampuan setiap anggota lain. Untuk mencapai kinerja yang tinggi memerlukan waktu lama untuk membangunya, memerlukan kepercayaan, dan menuntut perhatian yang seksama dari pihak manajemen.

\section{Aspek-Aspek Standar Kinerja}

Umar dalam Mangkunegara (2005:18) membagi aspek-aspek kinerja sebagai berikut, Mutu pekerjaan, kejujuran karyawan, inisiatif, kehadiran, sikap, kerjasama, keandalan, pengetahuan tentang pekerjaan, tanggung jawab, dan pemanfaatan waktu kerja.

Oleh Mangkunegara (2005:18) dikemukakan bahwa "Aspek-aspek standar pekerjaan terdiri dari aspek kuantitatif dan aspek kualitatif."

Adapun aspek kuantitatif meliputi hal-hal seperti proses kerja dan kondisi pekerjaan, waktu yang dipergunakan atau lamanya melaksanakan pekerjaan, jumlah kesalahan dalam melaksanakan pekerjaan, jumlah dan jenis pemberian pelayanan dalam bekerja. Sedangkan aspek kualitatif meliputi ketetapan kerja dan kualitas pekerjaan, tingkat kemampuan dalam bekerja, kemampuan menganalisis data/informasi, kemampuan atau kegagalan mengunakan mesin atau peralatan, dan kemampuan mengevaluasi (keluhan konsumen). (Mangkunegara, 2005:18). 
Mitchell (dalam Sedarmayanti, 2001) menyatakan bahwa kinerja meliputi beberapa aspek, sebagai berikut.

1. Kualitas kerja / Quality of work

2. Ketepatan / Promptness

3. Inisiatif / Initiative

4. Kemampuan / Capability

5. Komunikasi / Communication

\section{HIPOTESIS}

Hipotesis dalam penelitian ini sebagai berikut: Ada pengaruh positif dari motivasi eksternal dan motivasi internal terhadap kinerja karyawan .

\section{METODE PENELITIAN}

\section{Populasi, Sampel, dan Metode Pengambilan Sampel}

Penelitian ini menggunakan metode survei untuk mengumpulkan data yang diolah. Populasi dalam penelitian ini adalahseluruh karyawan di TK Budi Mulia Dua Pandeansari. Pengambilan sampel dilakukan dengan total sampling (sensus) yaitu pemilihan sampel berdasarkan keseluruhan dari populasi dengan pertimbangan karena populasi karyawan hanya berjumlah 50 orang.

\section{Model Penelitian}

Model atau pola penelitian digunakan untuk mempermudah memahami alur penelitian adalah sebagai berikut:

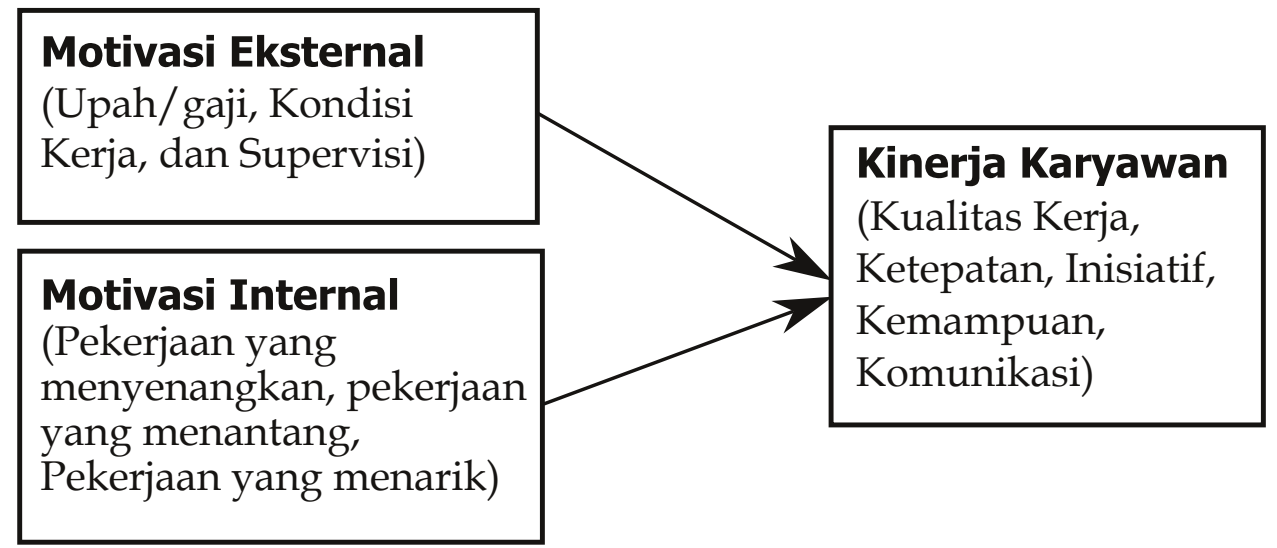

Kedua variabel independent tersebut akan diteliti pengaruhya baik secara bersamaan atau parsial terhadap kinerja karyawan. 


\section{Pengujian Instrumen Penelitian}

\section{a. Uji Validitas}

Pengujian validitas menggunakan Bivariate Correlation Pearson yang dilakukan dengan menghitung korelasi antar masing-masing skor item pertanyaan dari tiap variabel dengan total skor variabel tersebut. Untuk penelitian ini, nilai $\mathrm{df}$ dapat dihitung sebagai berikut $\mathrm{df}=\mathrm{n}-\mathrm{k}$ atau $50-6=$ 48, dengan tingkat signifikansi sebesar 0,05 maka didapat $r$ tabel sebesar 0,279 (one tail). Hasil pengujian validitas dapat dilihat pada tabel berikut ini:

Tabel Hasil Uji Validitas

\begin{tabular}{|c|c|c|c|c|c|}
\hline Item & $r$ hitung & Valid/Tidak & Item & r hitung & Valid/Tidak \\
\hline \multicolumn{3}{|c|}{ Gaji/Upah } & \multicolumn{3}{|c|}{ Pekerjaan Menarik } \\
\hline $\mathrm{X} 11$ & 0,690 & Valid & $\mathrm{X} 71$ & 0,592 & Valid \\
\hline $\mathrm{X} 12$ & 0,563 & Valid & $\mathrm{X} 72$ & 0,808 & Valid \\
\hline $\mathrm{X} 13$ & 0,727 & Valid & $\mathrm{x} 73$ & 0,680 & Valid \\
\hline $\mathrm{X} 14$ & 0,821 & Valid & $\mathrm{X} 74$ & 0,804 & Valid \\
\hline $\mathrm{X} 15$ & 0,727 & Valid & \multicolumn{3}{|c|}{ Kualitas Kerja } \\
\hline $\mathrm{X} 16$ & 0,738 & Valid & $\mathrm{Y} 11$ & 0,675 & Valid \\
\hline $\mathrm{X} 17$ & 0,684 & Valid & Y12 & 0,517 & Valid \\
\hline \multicolumn{3}{|c|}{ Kondisi Kerja } & Y13 & 0,655 & Valid \\
\hline $\mathrm{X} 21$ & 0,64 & Valid & Y14 & 0,772 & Valid \\
\hline $\mathrm{X} 22$ & 0,723 & Valid & Y15 & 0,659 & Valid \\
\hline$x 23$ & 0,571 & Valid & \multicolumn{3}{|c|}{ Ketepatan } \\
\hline $\mathrm{X} 24$ & 0,666 & Valid & $\mathrm{Y} 21$ & 0,751 & Valid \\
\hline $\mathrm{X} 25$ & 0,663 & Valid & $\mathrm{Y} 22$ & 0,619 & Valid \\
\hline \multicolumn{3}{|c|}{ Supervisi } & Y23 & 0,647 & Valid \\
\hline X31 & 0,727 & Valid & Y24 & 0,748 & Valid \\
\hline $\mathrm{X} 32$ & 0,697 & Valid & $\mathrm{Y} 25$ & 0,642 & Valid \\
\hline $\mathrm{X} 33$ & 0,764 & Valid & \multicolumn{3}{|c|}{ Inisiatif } \\
\hline $\mathrm{X} 34$ & 0,693 & Valid & Y31 & 0,799 & Valid \\
\hline $\mathrm{X} 41$ & 0,460 & Valid & Y32 & 0,727 & Valid \\
\hline $\mathrm{X} 42$ & 0,578 & Valid & Y33 & 0,638 & Valid \\
\hline $\mathrm{X} 43$ & 0,655 & Valid & Y34 & 0,765 & Valid \\
\hline \multicolumn{3}{|c|}{ Pekerjaan menyenangkan } & \multicolumn{3}{|c|}{ Kemampuan } \\
\hline $\mathrm{X} 51$ & 0,744 & Valid & Y41 & 0,756 & Valid \\
\hline $\mathrm{x} 52$ & 0,754 & Valid & $\mathrm{Y} 42$ & 0,659 & Valid \\
\hline $\mathrm{X} 53$ & 0,596 & Valid & Y43 & 0,750 & Valid \\
\hline $\mathrm{X} 54$ & 0,639 & Valid & Y44 & 0,645 & Valid \\
\hline \multicolumn{3}{|c|}{ Pekerjaan Menantang } & Y45 & 0,604 & Valid \\
\hline $\mathrm{x} 61$ & 0,688 & Valid & \multicolumn{3}{|c|}{ Komunikasi } \\
\hline $\mathrm{x} 62$ & 0,526 & Valid & Y51 & 0,675 & Valid \\
\hline$x 63$ & 0,600 & Valid & Y52 & 0,714 & Valid \\
\hline $\mathrm{x} 64$ & 0,632 & Valid & Y53 & 0,790 & Valid \\
\hline $\mathrm{x} 65$ & 0,585 & Valid & & & \\
\hline
\end{tabular}




\section{b. Uji Reliabilitas}

Uji reliabilitas digunakan untuk mengukur konsistensi konstruk/variable penelitian. Suatu variabel dikatakan reliable (handal) jika jawaban responden terhadap pertanyaan konsisten atau stabil dari waktu ke waktu. Tingkat reliabilitas suatu konstruk / variabel penelitian dapat dilihat dari hasil statistik Cronbach Alpha (a) Suatu variabel dikatakan reliable jika memberikan nilai cronbach alpha > 0,60 (Ghozali, 2005). Hasil perhitungan reliabilitas dapat dilihat pada berikut ini:

Tabel Hasil Uji Reliabilitas

\begin{tabular}{|c|c|c|}
\hline Item & $\begin{array}{l}\text { Cronbach's } \\
\text { Alpha if Item } \\
\text { Deleted }\end{array}$ & Keterangan \\
\hline \multicolumn{3}{|c|}{ Gaji/Upah } \\
\hline $\mathrm{x} 11$ & 0,929 & Reliabel \\
\hline $\mathrm{X} 12$ & 0,932 & Reliabel \\
\hline $\mathrm{X} 13$ & 0,928 & Reliabel \\
\hline $\mathrm{X} 14$ & 0,926 & Reliabel \\
\hline $\mathrm{X} 15$ & 0,928 & Reliabel \\
\hline $\mathrm{X} 16$ & 0,928 & Reliabel \\
\hline $\mathrm{X} 17$ & 0,929 & Reliabel \\
\hline \multicolumn{3}{|c|}{ Kondisi Kerja } \\
\hline$\times 21$ & 0,929 & Reliabel \\
\hline $\mathrm{X} 22$ & 0,928 & Reliabel \\
\hline $\mathrm{X} 23$ & 0,931 & Reliabel \\
\hline$\times 24$ & 0,930 & Reliabel \\
\hline X25 & 0,930 & Reliabel \\
\hline \multicolumn{3}{|c|}{ Supervisi } \\
\hline X31 & 0,928 & Reliabel \\
\hline X32 & 0,929 & Reliabel \\
\hline X33 & 0,927 & Reliabel \\
\hline X34 & 0,929 & Reliabel \\
\hline $\mathrm{X} 41$ & 0,935 & Reliabel \\
\hline$x 42$ & 0,931 & Reliabel \\
\hline $\mathrm{X} 43$ & 0,930 & Reliabel \\
\hline \multicolumn{3}{|c|}{ Pekerjaan menyenangkan } \\
\hline $\mathrm{X} 51$ & 0,883 & Reliabel \\
\hline$\times 52$ & 0,882 & Reliabel \\
\hline $\mathrm{X} 53$ & 0,890 & Reliabel \\
\hline$\times 54$ & 0,888 & Reliabel \\
\hline \multicolumn{3}{|c|}{ Pekerjaan Menantang } \\
\hline $\mathrm{x} 61$ & 0,886 & Reliabel \\
\hline $\mathrm{x} 62$ & 0,895 & Reliabel \\
\hline$x 63$ & 0,891 & Reliabel \\
\hline$x 64$ & 0,890 & Reliabel \\
\hline$x 65$ & 0,891 & Reliabel \\
\hline
\end{tabular}

\begin{tabular}{|c|c|c|}
\hline Item & $\begin{array}{l}\text { Cronbach's } \\
\text { Alpha if Item } \\
\text { Deleted }\end{array}$ & Keterangan \\
\hline \multicolumn{3}{|c|}{ Pekerjaan Menarik } \\
\hline $\mathrm{X} 71$ & 0,891 & Reliabel \\
\hline $\mathrm{X} 72$ & 0,879 & Reliabel \\
\hline $\mathrm{X} 73$ & 0,886 & Reliabel \\
\hline$X 74$ & 0,880 & Reliabel \\
\hline \multicolumn{3}{|c|}{ Kualitas Kerja } \\
\hline Y11 & 0,945 & Reliabel \\
\hline $\mathrm{Y} 12$ & 0,947 & Reliabel \\
\hline Y13 & 0,946 & Reliabel \\
\hline Y14 & 0,944 & Reliabel \\
\hline Y15 & 0,945 & Reliabel \\
\hline \multicolumn{3}{|c|}{ Ketepatan } \\
\hline Y21 & 0,944 & Reliabel \\
\hline Y22 & 0,946 & Reliabel \\
\hline $\mathrm{Y} 23$ & 0,946 & Reliabel \\
\hline Y24 & 0,944 & Reliabel \\
\hline Y25 & 0,946 & Reliabel \\
\hline \multicolumn{3}{|c|}{ Inisiatif } \\
\hline Y31 & 0,943 & Reliabel \\
\hline Y32 & 0,944 & Reliabel \\
\hline Y33 & 0,946 & Reliabel \\
\hline Y34 & 0,944 & Reliabel \\
\hline \multicolumn{3}{|c|}{ Kemampuan } \\
\hline Y41 & 0,944 & Reliabel \\
\hline Y42 & 0,945 & Reliabel \\
\hline Y43 & 0,944 & Reliabel \\
\hline Y44 & 0,946 & Reliabel \\
\hline Y45 & 0,946 & Reliabel \\
\hline \multicolumn{3}{|c|}{ Komunikasi } \\
\hline Y51 & 0,945 & Reliabel \\
\hline Y52 & 0,945 & Reliabel \\
\hline Y53 & 0,943 & Reliabel \\
\hline
\end{tabular}

Sumber: Data primer diolah Maret 2014 


\section{ANALISIS DATA}

\section{a. Analisis Regresi}

Hasil analisis regresi linear berganda pengaruh komponen variabel Kualitas Layanan terhadap Kepuasan Konsumen ditunjukan dalam tabel berikut:

Tabel Hasil Regresi Linear Berganda

\begin{tabular}{|c|r|r|r|r|}
\hline \multicolumn{1}{|c|}{ Model Summary } \\
\hline Model & $\mathrm{R}$ & $\mathrm{R}$ Square & $\begin{array}{c}\text { Adjusted R } \\
\text { Square }\end{array}$ & Std. Error of the Estimate \\
\hline 1 & $.769^{\mathrm{a}}$ & .592 & .575 & \\
\hline
\end{tabular}

a. Predictors: (Constant), Motivasi internal (X2), Motivasi eksternal (X1)

b. Dependent Variable: Kinerja (Y)

\begin{tabular}{|c|c|c|c|c|c|c|}
\hline \multicolumn{7}{|c|}{ ANOVA $^{a}$} \\
\hline & Model & Sum of Squares & df & Mean Square & $\mathrm{F}$ & Sig. \\
\hline & Regression & 4589.538 & 2 & 2294.769 & 34.085 & $.000^{\mathrm{a}}$ \\
\hline 1 & Residual & 3164.242 & 47 & 67.324 & & \\
\hline & & 7753.780 & 49 & & & \\
\hline
\end{tabular}

a. Dependent Variable: Kinerja (Y)

b. Predictors: (Constant), Motivasi internal (X2), Motivasi eksternal (X1)

\begin{tabular}{|c|c|c|c|c|c|c|}
\hline \multicolumn{7}{|c|}{ Coefficients $^{a}$} \\
\hline & \multirow{2}{*}{ Model } & \multicolumn{2}{|c|}{ Unstandardized Coefficients } & \multirow{2}{*}{$\begin{array}{c}\begin{array}{c}\text { Standardized } \\
\text { Coefficients }\end{array} \\
\text { Beta }\end{array}$} & \multirow{2}{*}{$\mathrm{t}$} & \multirow{2}{*}{ Sig. } \\
\hline & & B & Std. Error & & & \\
\hline \multirow{3}{*}{1} & (Constant) & 8.641 & 9.319 & & .927 & .359 \\
\hline & Motivasi eksternal (X1) & .703 & .131 & .594 & 5.361 & .000 \\
\hline & Motivasi internal (X2) & .450 & .189 & .264 & 2.388 & .021 \\
\hline
\end{tabular}

a. Dependent Variable: Kinerja (Y)

Sumber: Data primer diolah,2014

Berdasarkan hasil analisis regresi pada tabel tersebut dapat disusun model persamaan regresi linear berganda pengaruh komponen variabel Kualitas Layanan terhadap Kepuasan Konsumen sebagai berikut:

$$
\mathrm{Y}=8,641+0,703 \times 1+0,450 \mathrm{X2}
$$

Keterangan:

$\mathrm{Y}=$ Kinerja karyawan

X1 = Motivasi Eksternal

$\mathrm{X} 2=$ Motivasi Internal 
Pada tabel hasil analisis regresi dapat dilihat bahwa nilai Determinan (Adjusted $R$ Square) adalah sebesar 0,575 atau 57,5\%. Berarti bahwa variabel Motivasi Eksternal dan Motivasi Internal dapat menjelaskan variabel dependent (Kinerja Karyawan) sebesar 57,5\%, sedangkan sisanya $(42,5 \%)$ diterangkan oleh faktor lain yang tidak diteliti.

\section{b. Uji F}

Uji F bertujuan untuk mengetahui apakah variabel independen secara bersama-sama berpengaruh signifikan terhadap variabel dependent. Hipotesis untuk uji F sebagai berikut:

Ho $: b_{1}, b_{2}=0$ (Artinya variabel motivasi eksternal dan motivasi internal secara bersama-sama tidak berpengaruh terhadap kinerja karyawan).

Ha $: b_{1}, b_{2} \neq 0$ (Artinya variabel motivasi eksternal dan motivasi internal secara bersama-sama berpengaruh terhadap kinerja karyawan).

Dalam pengujian ini Ho ditolak bila nilai $\mathrm{F}$ hitung $>\mathrm{F}$ tabel.

Dari hasil uji $\mathrm{F}$ pada penelitian ini didapatkan nilai $\mathrm{F}$ hitung sebesar 34,085. Dengan tingkat signifikansi 95\% $(\alpha=0,05)$, dan d.f $=n-k-1=50$ $-2-1=47$, sehingga nilai $\mathrm{F}$ tabel adalah 3,195. Nilai $\mathrm{F}$ hitung $>\mathrm{F}$ tabel (34,085> 3,195), artinya variabel Motivasi Eksternal dan Motivasi Internalsecara bersama-samamempunyai pengaruh yang signifikan terhadap variabel Kinerja Karyawan.

\section{c. Uji t}

Uji t digunakan untuk mengetahui pengaruh secara parsial masingmasing variabel Motivasi Eksternal dan Motivasi Internalterhadap variabel dependent (Kinerja Karyawan). Hipotesis untuk uji t sebagai berikut:

Ho $: b_{1}=0$ (Motivasi eksternal secara parsial tidak berpengaruh terhadap kinerja karyawan).

Ha $: b_{1} \neq 0$ (Motivasi eksternal secara parsial berpengaruh terhadap kinerja karyawan).

Dalam pengujian ini Ho ditolak bila nilai $t$ hitung $>t$ tabel.

Dalam pengujian ini digunakan tingkat signifikansi $95 \%(\alpha=0,05)$, dan d.f $=n-k=50-3=47$ sehingga nilai $t$ tabel adalah 2,012. Pada tabel hasil analisis regresi dapat dilihat bahwa nilai untuk $t$ hitung variabel Motivasi Eksternal dan Motivasi Internal lebih besar dari 2,012,artinya secara parsial Motivasi Eksternal dan Motivasi Internal berpengaruh signifikan terhadap Kinerja Karyawan. 


\section{UJI ASUMSI KLASIK}

\section{a. Uji Normalitas Residual}

Uji ini dilakukan untuk mengetahui apakah dalam sebuah model regresi, nilai residual memiliki distribusi normal atau tidak. Dalam metode regresi linier, hal ini ditunjukkan oleh besarnya nilai random error (e) yang berdistribusi normal. Model regresi yang baik adalah yang terdistribusi secara normal atau mendekati normal sehingga data layak untuk diuji secara statistik.

Cara untuk mendeteksinya adalah dengan melihat penyebaran data pada sumber diagonal pada grafik Normal P-P Plot of regression standardized sebagai dasar pengambilan keputusannya. Jika menyebar sekitar garis dan mengikuti garis diagonal maka model regresi tersebut telah normal dan layak dipakai untuk memprediksi variabel bebas dan sebaliknya. (Ghozali, 2005).

Hasil uji normalitas dapat dilihat pada grafik Normal P-P Plot di bawah ini:

\section{Normal P-P Plot of Regression Standardized Residual}

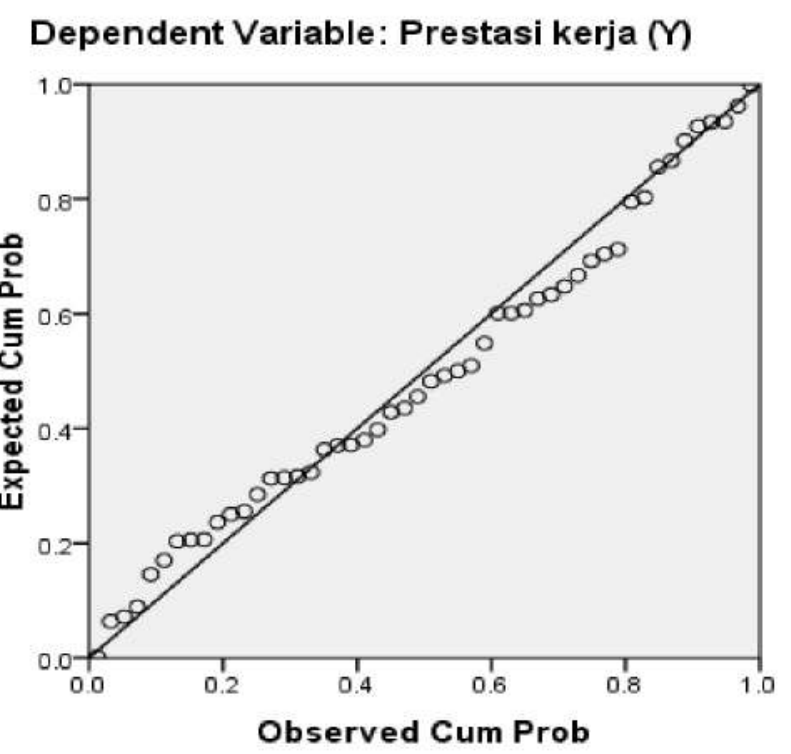

Sumber : Data diolah, 2014

Dari gambar di atas, dapat diketahui bahwa titik-titik menyebar sekitar garis dan mengikuti garis diagonal maka model regresi tersebut telah normal. 


\section{b. Uji Multikolinieritas}

Uji ini dilakukan untuk mengetahui adanya hubungan yang sempurna atau mendekati sempurna (koefisien korelasi tinggi) antar variabel bebas (independent variables) dalam suatu model regresi berganda. Suatu model regresi berganda yang mengandung derajat multikolinearitas yang tinggi menyebabkan kesalahan standar estimasi akan cenderung meningkat dengan bertambahnya variabel bebas.

Pengujian ada tidaknya gejala multikolinieritas dilakukan dengan memperhatikan nilai matriks korelasi yang dihasilkan pada saat pengolahan data serta nilai VIF (Variance Inflation Factor) dan Toleransinya. Apabila nilai VIF lebih kecil 10 dan nilai toleransi lebih besar dari 0,1 maka diambil kesimpulan bahwa model regresi tersebut tidak terdapat multikolinieritas (Singgih Santoso, 2000). Hasil uji Multikolinieritas dapat pada tabel berikut:

Tabel Hasil Pengujian Multikolinieritas

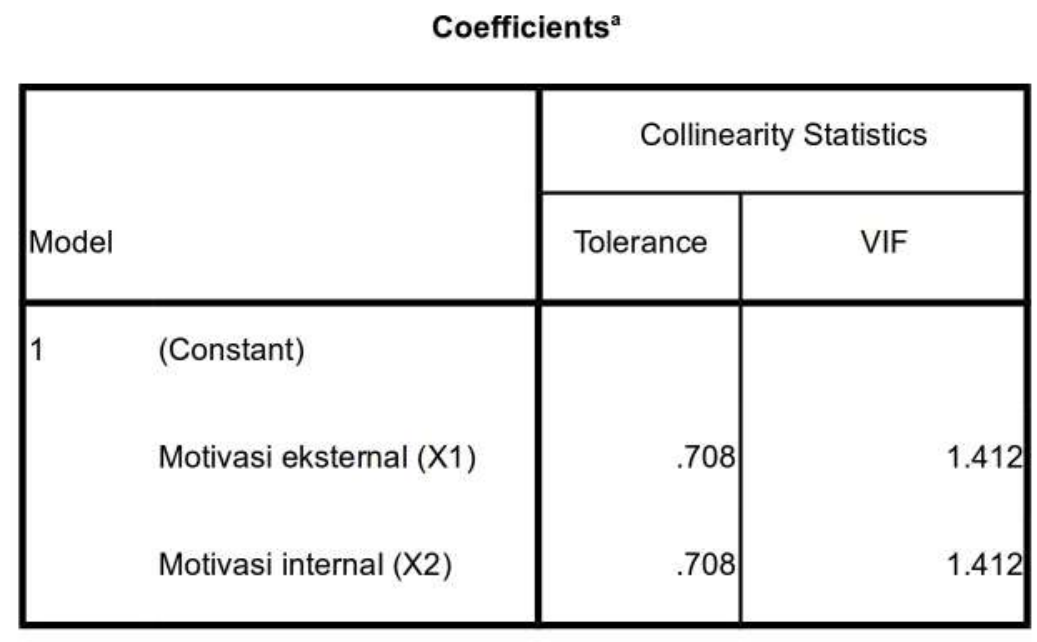

a. Dependent Variable: Kinerja Karyawan $(Y)$

Berdasarkan tabel di atas dapat dilihat bahwa model regresi tidak mengalami gangguan multikolinieritas. Hal ini tampak pada nilai tolerance masing-masing variabel lebih besar dari 0,1. Hasil perhitungan VIF juga menunjukkan bahwa nilai VIF masing-masing variabel kurang dari 10. Jadi dapat disimpulkan bahwa tidak ada multikolinieritas antar variabel bebas dalam model regresi tersebut. 


\section{c. Uji Heterokedastisitas}

Heteroskedastisitas adalah keadaan dimana terjadinya ketidaksamaan varian dari residual pada model regresi.(Priyatno, 2009). Model regresi yang baik mensyaratkan tidak adanya masalah heteroskedastisitas. Uji ini bertujuan untuk menguji apakah dalam sebuah model regresi, terjadi ketidaksamaan varians dari residual suatu pengamatan ke pengamatan lainnya. Jika varians dari residual suatu pengamatan ke pengamatan lainnya tetap, hal ini disebut Homoskedastisitas, namun jika variansnya berbeda, disebut Heteroskedastisitas.

Untuk mendeteksi ada tidaknya heterokedastisitas dengan melakukan uji Glejser. Uji Glejser ini dilakukan dengan meregresikan variablevariabel bebas terhadap nilai absolute residual. Sebagai pengertian dasar, residual adalah selisih antara nilai observasi dengan nilai prediksi, dan absolut adalah nilai mutlaknya. Jika nilai signifikansi antara variabel independen dengan residual lebih dari 0,05 maka tidak terjadi heteroskedastisitas. (Ghozali, 2005). hasil uji multikolinearitas disajikan sebagai berikut:

Tabel Hasil uji Multikolinearitas

Coefficients $^{\mathrm{a}}$

\begin{tabular}{|c|c|c|c|c|c|}
\hline \multirow[b]{2}{*}{ Model } & \multicolumn{2}{|c|}{ Unstandardized Coefficients } & \multirow{2}{*}{$\begin{array}{c}\text { Standardized } \\
\text { Coefficients } \\
\text { Beta }\end{array}$} & \multirow[b]{2}{*}{$t$} & \multirow[b]{2}{*}{ Sig. } \\
\hline & B & Std. Error & & & \\
\hline (Constant) & 12.593 & 6.019 & & 2.092 & .042 \\
\hline Motivasi eksternal (X1) & -.002 & .085 & -.004 & -.025 & .980 \\
\hline Motivasi internal (X2) & -.127 & .122 & -.178 & -1.044 & .302 \\
\hline
\end{tabular}

a. Dependent Variable: ABS_RES

Sumber : Data diolah, 2014

Hasil uji heteroskedastisitas dapat diketahui untuk kedua variabel independen nilai signifikansi lebih dari 0,05, sehingga dapat disimpulkan tidak ada masalah heteroskedastisitas pada model regresi. 


\section{KESIMPULAN dan SARAN}

Berdasarkan analisis data diperoleh kesimpulan bahwa Motivasi Eksternal dan Motivasi Internal berpengaruh positif dan signifikan terhadap Kinerja KaryawanTK Budi Mulia Dua Pandeansari Yogyakarta. Semakin tingggi Motivasi Eksternal dan Motivasi Internal yang diberikan organisasi kepada karyawan akan semakin meningkatkan Kinerja karyawan. Motivasi Eksternal (gaji/upah, kondisi kerja, dan supervisi) memberikan sumbangan terbesar dalam meningkatkan kinerja karyawan.

Berdasarkan kesimpulan yang diperoleh dari hasil analisis data penulis memberikan saran sebagai berikut:

Secara teoritis penelitian ini membuktikan konsep pengaruh Motivasi Eksternal dan Motivasi Internal terhadap Kinerja Karyawan. Untuk TK Budi Mulia Dua Pandeansari, variabel Motivasi Eksternal yang diberikan kepada karyawan agar mendapat perhatian, karena variabel ini sangat berpengaruh signifikan dalam meningkatkan kinerja karyawan di TK Budi Mulia Dua Pandeansari.

Bagi penelitian selanjutnya agar mempertimbangkan atau menambah indikator dalam pengukuran variabel motivasi eksternal, sehingga dimungkinkan memberikan kesimpulan hasil yang lebih baik. 


\section{DAFTAR PUSTAKA}

As'ad, Moh. 1995. Psikologi Industri: Seri Ilmu Sumber Daya Manusia, Yogyakarta, Liberty.

Ghozali, Imam. 2005. Aplikasi Analisis Multivariate dengan program SPSS. Semarang: Badan Penerbit Universitas Diponegoro.

Mangkunegara, Anwar Prabu. 2005. Manajemen Sumber daya manusia Perusahaan. PT.Remaja Rosda Karya. Bandung

Priyatno, Duwi, "5 Jam Belajar Olah Data Dengan SPSS 17", Cetakan Kedua, Yogyakarta: ANDI, 2010.

Santoso, Singgih. 2001. Buku Latihan SPSS Statistik Parametrik. PT.ELEK Media Komputindo. Jakarta

Sedarmayanti. 2001. Sumber daya manusia dan produktivitas kerja. CV. Pustaka Setia. Bandung

Sunarto, 2003. Perilaku Organisasi. Amus. Jakarta 